\title{
HISTÓRICO DA MEDICINA LEGAL
}

\author{
HISTORY OF LEGAL MEDICINE
}

Bruna Fernandes Coêlho

\begin{abstract}
Resumo:
A assertiva "não há como compreender de forma primorosa a Medicina Legal sem antes analisar o seu histórico" já demonstra p propósito dessa matéria que traça a trajetória desta fascinante Cadeira na área do Direito, desde a Antiguidade em tempos de sacerdotes que governavam à maneira da força e da evocação divina, passando pelo universo egípcio época em que cadáveres eram embalsamados em rituais complexos, despertando atenção de arqueólogos do mundo inteiro, no auxílio primaz de se compreender e decifrar a História da Humanidade. E os cadáveres, no Egito, eram considerados sagrados e, ainda são, nos dias atuais. A matéria prossegue narrando sobre as leis de Menés, o Código de Hamurabi que á a mais antiga legislação penal que se tem notícia, a Lei das XII Tábuas, do Império Romano, acrescentada de outros complementos que elencam a História da Medicina Legal.

Palavras-chave: Medicina Legal. História.
\end{abstract}

\begin{abstract}
:
The assertive "there is no way to understand how exquisite the forensic medicine without first analyzing your history" already demonstrates p purpose of this matter that traces the trajectory of this fascinating Chair in the right area, since antiquity in times of priests who ruled in the manner of divine strength and evocation, passing by the Egyptian universe when corpses were stuffed into complex rituals, arousing attention of archaeologists from all over the world, in primate to understand and decipher the history of mankind. And corpses, in Egypt, were considered sacred and are still, today.The story continues narrating about the laws of Menes, Hammurabi's code that will be the oldest criminal legislation that has news, the law of the XII boards, of the Roman Empire, other add-ons added: the history of forensic medicine.
\end{abstract}

Keywords: Legal Medicine. History.

Matéria que em poucos desperta interesse, o bojo histórico de uma Ciência deve ser analisado minuciosamente, tendo em vista alcançar a raiz de sua criação e, a partir da compreensão de seus fundamentos filosóficos, compreender a ciência em si. Não há como compreender e apreender de forma primorosa a Medicina Legal sem antes analisar o seu histórico, pois a importância de sua História representa a sua própria importância.

Bacharel em Direito pela Universidade Católica de Pernambuco (2007), Escrivã da Polícia Civil do Estado de Pernambuco, pós-graduanda em Direito Civil e Processual Civil pela Universidade Gama Filho (RJ); pósgraduanda em Direito Penal e Processual Penal pelo Instituto de Magistrados de Pernambuco; graduanda em Medicina Veterinária pela Universidade Federal Rural de Pernambuco. Currículo Lattes: http://lattes.cnpq. br/7399915688574739. E-mail: brunacoelho@terra.com.br. Convidada especial do Editor desta Revista; que recomenda aos historiadores do Direito a leitura, que por sua vez, foi aprovada pela Comissão de Publicação em outubro de 2010. 
O marco inicial da Medicina Legal não pode ser apontado com exatidão. Certamente, seu surgimento é posterior ao surgimento da Medicina.

Os primeiros indícios da íntima relação entre a Medicina e o Direito remontam da Antiguidade. ${ }^{1}$ Nestes tempos, os sacerdotes, que governavam à base da força e da evocação divina, eram concomitantemente legisladores, juízes e médicos. No entanto, necropsia e vivisseção eram proibidos, vez que os cadáveres eram considerados sagrados. ${ }^{2}$ No Egito, cadáveres eram embalsamados e, nos casos de crimes sexuais, o suspeito era condenado se, atado ao leito numa sala do templo, apresentava ereção diante da visão de virgens dançando nuas ou trajando vestes transparentes. ${ }^{3}$ As leis de Menés preceituavam o exame para verificação de gravidez, pois supliciar mulheres grávidas era vedado pela norma. ${ }^{4}$

O Código de Hamurabi, a mais antiga legislação penal de que se tem notícia, trazia em seu bojo normas que evidenciavam a relação entre Direito e Medicina. No entanto, não estipulava que o Juiz deveria ouvir o médico ao prolatar suas decisões. ${ }^{5} \mathrm{O}$ Código de Manu proibia que crianças, idosos, ébrios, indivíduos com desenvolvimento mental incompleto e pessoas insanas fossem ouvidas nos tribunais na condição de testemunha. ${ }^{6}$ No Império Romano, tal proibição surge com o disposto na Lei das XII Tábuas, que data de 449 a.C. Esta legislação determinava, inclusive, que o período máximo da gestação seria de dez meses, afora a postergação de julgamento por motivo de doença do julgador ou quaisquer das partes. ${ }^{7}$ Uma classificação de lesões corporais, com a finalidade de arbitrar multa ao agressor, era elencada nas leis da antiga Pérsia. ${ }^{8}$

O Hsi Yuan Lu, tratado chinês elaborado aproximadamente em 1240 a.C., prescrevia instruções acerca do exame post mortem, listava antídotos para venenos e apresentava informações sobre respiração artificial. ${ }^{9}$

De acordo com o que prescreve a crença, Numa Pompílio ordenou em Roma o exame médico na morte das grávidas: ${ }^{10}$ a Lex Regia determinava a histerectomia nos cadáveres das gestantes." Há quem acredite que o termo "cesariana" proveio do

GOMES, Hélio. Medicina legal. Atualizador Hygino Hercules. 33. ed. rev. e atual. Rio de Janeiro: Freitas Bastos, 2004. p. 18.

2 CROCE, Delton; CROCE JÚNIOR, Delton. Manual de medicina legal. 6. ed. rev. São Paulo: Saraiva, 2009. p. 5 .

3 Id. Ibid.

4 Id. Ibid.

3 GOMES, Hélio. Loc. cit.

Id. Ibid.

Id. Ibid.

Id. Ibid.

CROCE, Delton; CROCE JÚNIOR, Delton. Loc. cit.

10 FRANÇA, Genival Veloso de. Medicina legal. 8. ed. Rio de Janeiro: Guanabara Koogan, 2008. p. 3.

1 CROCE, Delton; CROCE JÚNIOR, Delton. Loc. cit. 
nascimento de César, resultado de uma histerectomia. Entretanto, estudiosos afirmam que o termo descende de coedo, que significa "cortar" 12

A primeira citação documental acerca de exame cadavérico em vítima de homicídio, segundo os relatos de Suetônio, ${ }^{13}$ refere-se à tanatoscopia realizada no cadáver do ditador romano Caio Júlio César. Por haver desprezado a opinião de seus adversários, em 15 de março de 44 a.C., o ditador foi vítima de um ataque provindo de sessenta de seus senadores, liderados por seu filho adotivo Marcus Julius Brutus e por Caio Cássio. ${ }^{14}$ O exame em tela foi realizado por Antístio, médico e amigo de Júlio César, que verificou a existência de 23 golpes de adaga, sendo apenas um deles mortal. No entanto, Antístio procedeu ao exame não como perito médico, mas como cidadão do Império Romano. ${ }^{15}$

De acordo com relatos de Tito Lívio, filósofo e historiador romano, o cadáver de Tarquínio, que morreu assassinado, e o de Germânico, suspeito de ser vítima de envenenamento, foram examinados por um médico. ${ }^{16}$ Faz-se relevante destacar que tais exames eram de viso, tendo em vista a ilegalidade dos exames cadavéricos na época.

Na Idade Média, se deve a Justiniano o reconhecimento dos médicos como testemunhas especiais em juízo, não sendo os juízes, entretanto, obrigados a ouvi-los. Já as Capitulares de Carlos Magno prescreviam que os julgamentos deveriam ser pautados em pareceres médicos, devendo os julgadores tomar depoimentos dos médicos nos casos de lesão corporal, infanticídio, tortura, estupro, impotência, etc. ${ }^{17}$ Apesar deste avanço em relação à valorização e reconhecimento desta área médica, as ordálias (?) configuram um retrocesso ao papel da Medicina ante a Justiça, uma vez que a prática nordo-germânica das provas inquisitoriais imputava o juízo de valor a Deus. ${ }^{18}$

No período denominado Canônico, a Medicina Legal sofreu forte influência do cristianismo, sendo restabelecido o concurso das perícias médicas pelo Papa Inocêncio III, no ano de 1209. ${ }^{19}$ As Decretais dos Pontífices dos Concílios (Peritorum indicio medicorum) tratam exaustivamente da sexologia, pois é nela que se fundamenta a moralidade ${ }^{20} \mathrm{O}$ médico passa a ter fé pública nos assuntos concernentes à sua profissão e as perícias passam a ser obrigatórias. A anulação do casamento por impotência enseja a denominada prova do congresso, posteriormente proibida em 1677 pelo Parlamento de França e que consistia em um exame realizado "por três parteiras e posteriormente por três

\footnotetext{
12 Id. Ibid. Loc. cit.

13 FRANÇA, Genival Veloso de. Loc. cit.

14 CALENDÁRIO histórico: 44 a.C.: assassinato do imperador Júlio César. [S.1.], [20--?]. Disponível em <http://www.dw-world.de/dw/article/0,781828,00.html $>$. Acesso em: 03 out. 2010.

is GOMES, Hélio. op. cit. p. 19.

16 CROCE, Delton; JÚNIOR, Delton Croce. Loc. cit.

17 GOMES, Hélio. Loc. cit.

18 CROCE, Delton; JÚNIOR, Delton Croce. op. cit. p. 05 - 06.

19 Id. Ibid. p. 6.

20 Id. Ibid.
} 
médicos que, separados do casal por uma cortina, em aposento contíguo, confirmavam a realização ou não da conjunção carnal, em burlesca caricatura de perícia" ${ }^{21}$ Jozefran Freire afirma que práticas rudimentares e poucos conhecimentos predominavam, o que demonstra "o esforço despendido por diversos autores na resolução de problemas que, embora originados no cotidiano, eram extremamente complexos, principalmente pelos parcos fundamentos científicos da época" 22

Em 1532 foi promulgada a Constitutio Criminalis Carolina, considerada o primeiro documento ordenado de Medicina Judiciária, que discorria exaustivamente acerca de temas médico-legais e previa a obrigatoriedade da ouvida dos médicos antes da prolação das sentenças. Em decorrência de tal legislação criminalista, a Alemanha é considerada o berço da Medicina Legal. Um dos maiores avanços da norma foi permitir a realização de exame tanatoscópico em caso de morte violenta. O corpo do Papa Leão $\mathrm{X}$ foi necropsiado por suspeita de morte por envenenamento ${ }^{23}$ Hélio Gomes afirma que a Constitutio Criminalis Carolina "abrigava o embrião da Medicina Legal como disciplina distinta e individualizada" ${ }^{24}$ Com a obrigatoriedade das perícias, a maior circulação de informações acerca do tema enseja a publicação das primeiras obras de valor sobre Medicina Legal no Ocidente. Os primeiros tratados sobre o tema começam a emergir na segunda metade do século XVI.

Fávero aponta como nascedouro da Medicina Legal o Edito della gran carta della Vicaria di Napoli, de 1525. A maioria dos autores aponta a Alemanha como berço da Medicina Legal enquanto ciência. Fávero afirma:

No século XVIII, a Medicina Legal se instituiu como disciplina científica e, daí para cá, se aprofundou em realizações, pelas três escolas rivais, que disputam a supremacia - a francesa, sintética e original, a alemã, analítica e erudita, e a italiana, reunindo às vantagens do gênio latino o amor às minudências da escola alemã. ${ }^{25}$

Em 1575 Ambroise Paré lança o primeiro tratado ocidental sobre Medicina Legal, intitulado Des Rapports et des Moyens d'Embaumer lês Corps Morts, ${ }^{26}$ "e a França aclama seu autor como o pai da Medicina Forense, a despeito de a obra, de inegável valor, não constituir corpo doutrinário e sistemático" ${ }^{27}$ Apesar do título, a obra discorre sobre gravidade de feridas, formas de asfixia, diagnóstico de virgindade e outras questões nesta linha. Em 1598, Séverin Pineau afirma em seu livro que o hímem pode permanecer

\footnotetext{
Id. Ibid.

FREIRE, José Jozefran Berto. op. cit. p. 24.

FRANÇA, Genival Veloso de. op. cit. p. 4.

GOMES, Hélio. Loc. cit.

FREIRE, José Jozefran Berto. Loc. cit.

Relatórios e fundamentos de embalsamamento de cadáveres (Tradução nossa).

27 CROCE, Delton; CROCE JÚNIOR, Delton. op. cit. p. 7.
} 
intacto após a conjunção carnal - eis a primeira alusão na literatura médica ao hímem complacente.

Fortunato Fidelis, em 1602, publicou em Palermo obra mais aprofundada e detalhada, denominada De Relatoribus Libri Quator in Quibis ea Omnia quae in Forensibus ae Publicis Causis Medici Preferre Solent Plenissime Traduntur. A obra, dividida em quatro volumes, tratava respectivamente de saúde pública; ferimentos, simulação de doenças e erro médico; virgindade, impotência, gravidez̧ e viabilidade fetal e, finalmente, sobre vida e morte, fulguração e envenenamento. Fidelis defendia a execução de necrópsias completas, diversas daquelas anteriormente mencionadas.

Obra que se revelou se suma relevância foi a do romano Paulus Zacchias, que se constituiu em dez livros publicados entre os anos de 1621 e 1658. À época, os livros que versavam sobre Medicina Legal a relacionavam à saúde pública, o que não foi o caso da obra de Zacchias. Esta coletânea serviu de referência ao estudo da Medicina Legal até o início do século XIX. Foi neste século que a Medicina Legal se firmou pautada no conceito que a Justiça lhe atribuiu: o de produzir provas através da Ciência. Tal se confirma nos dizeres de Hélio Gomes:

A partir da segunda metade do século XIX, a aplicação do método científico às ciências biológicas modificou a postura dos médicos com relação às doenças. Paulatinamente, foram surgindo as especialidades clínicas e cirúrgicas. A Medicina Legal, como caudatária deste desenvolvimento, passou a ser considerada como ciência, uma forma de medicina aplicada. ${ }^{28}$

Em 1823 Orfila aponta a Medicina Legal como o ramo da Medicina voltado para a Justiça, ocupando-se das causas levadas aos tribunais. Toda a trajetória da Medicina Legal ao longo de sua História a transformou em elemento basilar para a jurisdição e alcance do escopo da Justiça.

\section{HISTÓRICO DA MEDICINA LEGAL NO BRASIL}

O Brasil iniciou seus estudos no campo da Medicina Legal tardiamente em relação à Europa. Apesar da influência portuguesa no meio intelectual e cultural, Portugal não influenciou o país no campo da Medicina Legal, uma vez que, em tal país, àquela época, os estudos médico-legais não eram satisfatoriamente desenvolvidos.

No fim da era colonial aparecem os primeiros documentos médico-legais no país, frutos de estudos influenciados pela França e, um tanto mais sutilmente, pela Itália e pela Alemanha. A primeira publicação de documento médico-legal brasileiro, da

${ }_{28}$ GOMES, Hélio. op. cit. p. 21. 
fase nacionalista da consolidação de tal ciência no país, data de 1814. Neste documento, Gonçalves Gomide, médico e senador do Império, contesta parecer exarado por dois outros médicos. ${ }^{29}$ Agostinho José de Souza Lima assume o ensino prático da disciplina na Faculdade de Medicina do Rio de Janeiro e, sem ter conhecimento na área jurídica, interpreta a legislação brasileira à luz dos conhecimentos médico-legais da época, sendo por isso considerado pioneiro em Medicina Legal em nossa pátria.

Neste período histórico, os juízes não eram obrigados a consultar médicos antes de proferir sentenças. Esta obrigação surgiu com o advento do Código Penal do Império, datado de 16 de dezembro de $1830 .{ }^{30}$ No ano de 1832, o ramo do Processo Penal ${ }^{13}$ é estruturado no país, trazendo à lume normas acerca dos exames de corpo de delito, instituindo oficialmente a perícia médica criminal. Muitas destas determinações primordiais ainda se encontram em vigor no texto moderno da norma procedimental penal. Neste mesmo ano, tornam-se faculdades oficiais de Medicina as da Bahia e do Rio de Janeiro, fazendo parte da grade curricular do curso, em ambas as instituições de ensino superior, a disciplina de Medicina Legal. Estudos nessa área afloraram por conta da exigência da defesa de tese para a obtenção do título de doutor em Medicina. ${ }^{32}$

A primeira publicação versando sobre exame tanatológico no Brasil data de 21 de setembro de 1835 e relata a necropsia realizada no Regente João Bráulio Moniz (que havia morrido 22 horas antes da realização do exame), executada pelo cirurgião da família imperial, Hércules Otávio Muzzi. ${ }^{33}$

Em 1854, o mais antigo catedrático de Medicina Legal da Faculdade Médica do Rio de Janeiro, o conselheiro José Martins da Cruz Jobim, foi imbuído, pelo Ministro da Justiça, da missão de coordenar comissão para uniformizar a prática dos exames médicolegais, organizando uma tabela prognóstica das lesões corporais. ${ }^{34}$

No ano de $1856,{ }^{35}$ foi regulamentada a atividade médico-legal através do Decreto n. 1.746, de 16 de abril do referido ano, "quando se criou, junto à Secretaria de

29 GOMES, Hélio. Medicina legal. Atualizador Hygino Hercules. 33. ed. rev. e atual. Rio de Janeiro: Freitas Bastos, 2004. p. 22.

30 IMPÉRIO DO BRAZIL. Lei de 16 de dezembro de 1830. Manda executar o Código Criminal. Lex: Código Criminal do Imperio do Brazil. Disponível em: <http:/www.planalto.gov.br/ccivil/leis/LIM/LIM-16-121830.htm>. Acesso em: 04 out. 2010.

31 Id. Ibid. Lei de 29 de novembro de 1832. Promulga o Código Criminal de primeira instância com disposição provisória acerca da administração da Justiça Civil. Lex: Código de Processo Penal de primeira instancia. Disponível em: <http://www.planalto.gov.br/ccivil_03/Leis/LIM/LIM-29-11-1832.htm>. Acesso em: 4 out. 2010.

32 GOMES, Hélio. Loc. cit.

33 Id. Ibid.

34 Id. Ibid.

35 França aponta o ano como sendo o de 1854. Já Hélio Gomes (Op. cit. p. 22) aponta a data como sendo de 1856. A dúvida pode ser sanada se nos remetermos ao Decreto ${ }^{\circ} 1.746$ de 16 de abril de 1856 . Disponivel em: <http:/ books.google.com.br/books?id=zcMGAAAAYAAJ\&pg=RA1-PR7\&lpg=RA1-PR7\&dq=1856+secretaria+de+pol 
Polícia da Corte, a Assessoria Médico-Legal, à qual cabia a realização dos exames de corpo de delito e quaisquer exames necessários para a averiguação dos crimes e dos fatos como tais suspeitados" ${ }^{36}$ A assessoria era composta por quatro médicos, dos quais dois eram membros efetivos e incumbidos de proceder aos exames periciais e os dois outros eram professores de Medicina Legal e ocupavam o cargo de consultores, se responsabilizando, eminentemente, pelos exames toxicológicos. Neste mesmo ano, para atender a demanda dos exames a se realizar, "foi criado o primeiro necrotério do Rio de Janeiro no depósito de mortos de Gamboa, usado até então para guardar cadáveres de escravos, indigentes e presidiários" ${ }^{37}$

Em 1877, Agostinho José de Souza Lima, em conjunto com seu assistente, Borges da Costa, é nomeado consultor da polícia e, em 1879, é autorizado a ministrar um curso prático de tanatologia forense no necrotério oficial. ${ }^{38}$

A partir de 1891, a disciplina de Medicina Legal passa a configurar como obrigatória nos cursos de Direito do país. A inclusão foi proposta por Rui Barbosa perante a Câmara dos Deputados e, felizmente, conseguiu a aprovação. Para os estudantes de Direito, este é um marco na História do curso jurídico, tendo em vista que é de fundamental importância que o bacharel possua, ao menos, noções acerca da Ciência médico-legal. Se o papel da Medicina Legal como alicerce jurisdicional já se havia estabelecido, imprescindível se faz o estudo da disciplina em questão.

A fase de desenvolvimento e consolidação dita nacionalista da Medicina Legal teve como protagonista Raymundo Nina Rodrigues, considerado o maior professor de Medicina Legal do século XIX. O catedrático defendia a feitura de concursos públicos a fim de nomear peritos oficiais, "a fim de que se tornasse a justiça mais bem servida e imune aos erros de avaliação e interpretação comuns à atividade pericial de seu tempo" 39 As obras de Nina Rodrigues tiveram repercussão e reconhecimento internacionais. O insigne estudioso e mestre faleceu em Paris, aos 17 de julho de 1906.

Em 1900 é criado serviço de identificação antropométrica (identificação a partir das qualidades físicas particulares de um indivíduo) e a assessoria médica da polícia é transmutada em Gabinete Médico-Legal. Em antagonia a este avanço, nos cursos de Medicina Legal do país avaliações práticas da disciplina em análise deixam de ser obrigatórias. Dois anos depois, Afrânio Peixoto propõe uma reforma no Gabinete Médico-Legal, inspirado em suas observações na Alemanha, afirmando que o conjunto

$\% \mathrm{C} 3 \% \mathrm{ADcia}+\mathrm{da}+$ corte\&source=bl\&ots=LnmuKGDPvW\&sig-yDWAJlr8hFiM4jnTc6jfCct4kBE\&hl=pt-BR\&ei= kUuqTOLuI8G88gaGu9XaDA\&sa $=X \&$ oi=book_result\&ct-result\&resnum $=3 \&$ ved $=0 \mathrm{CB} 4 \mathrm{Q} 6 \mathrm{AEwAg \# v=onepage}$ $\& q=1856 \% 20$ secretaria $\% 20 \mathrm{de} \% 20$ pol\%C3\%ADcia\%20da\%20corte\&f-false $>$. Acesso em: 04 out. 2010.

36 FRANÇA, Genival Veloso de. Medicina legal. 8. ed. Rio de Janeiro: Guanabara Koogan, 2008. p. 06.

37 GOMES, Hélio. Loc. cit.

38 Id. Ibid. p. 23.

39 Id. Ibid. 
das "monstruosidades alcunhadas de termos de autópsias [sic], autos de corpo de delito confusos, desordenados, incoerentes, dando um triste atestado de incompetência profissional e prejudicando os interesses da justiça"40 é característica inerente à prática médico-legal do período. Influenciado por esta afirmação, o governo federal edita o Decreto n. 4.864 , de 15 de junho de $1903,{ }^{41}$ que discorre detalhadamente sobre as normas de procedimento das perícias médicas. Tal legislação foi considerada tão avançada para a época que Locard e Lombroso apregoavam que França e Itália deveriam se espelhar na norma brasileira. No entanto, as determinações prescritas no Decreto permaneciam em desuso e médicos não especializados eram convocados em juízo para apresentar laudos. Ante os protestos da Academia Nacional de Medicina e do Instituto dos Advogados do Brasil, o Decreto n. 6.440, de 30 de março de $1907^{42}$ transforma o aludido Gabinete em Serviço Médico-Legal, sendo nomeado Afrânio Peixoto como seu primeiro diretor.

Em 1915 a Lei Maximiliano confere legitimidade para serem procedidas aulas práticas nas Faculdades de Medicina e reconhece a validade jurídica dos laudos então elaborados. ${ }^{43}$ Ainda no tocante à validade jurídica dos laudos periciais, em 1924 o Serviço Médico-Legal se transforma no Instituto Médico-Legal, e se subordina diretamente ao Ministério da Justiça. O referido Instituto, ao fim do governo de Washington Luís, volta a se subordinar ao chefe de polícia do Distrito Federal.

A vigência do Código de Processo Penal de 1941, ${ }^{44}$ em vigor até os dias atuais, determina que as perícias sejam procedidas apenas por peritos oficiais. Em 20 de outubro de 1967 foi fundada a Associação Brasileira de Medicina Legal, sendo hoje a Medicina Legal reconhecida pelo Conselho Federal de Medicina, pela Associação Médica Brasileira e pela Comissão Nacional de Residência Médica do Ministério da Educação como especialidade médica. ${ }^{45}$

Pernambuco, dezembro de 2010.

40 GOMES, Hélio. Loc. cit

4 REPUBLICA DOS ESTADOS UNIDOS DO BRAZIL. Decreto n. 4.864, de 15 de junho de 1903. Manda observar o regulamento para o serviço médico-legal do Distrito Federal. Disponivel em <http://www2. camara.gov.br/legin/fed/decret/1900-1909/decreto-4864-15-junho-1903-508952-publicacao-1-pe.html>. Acesso em 04 de out. de 2010.

42 Id. Ibid. Decreto n. 6.440, de 30 de março de 1907. Dá novo regulamento ao serviço policial do Distrito Federal. Disponível em <http://www2.camara.gov.br/legin/fed/decret/1900-1909/decreto-6440-30-marco1907-504445-publicacao-1-pe.html>. Acesso em: 4 out. 2010.

43 GOMES, Hélio. op. cit. p. 24

44 BRASIL. Decreto-Lei n. 3.689, de 03 de outubro de 1941. Código de Processo Penal. Disponível em: <http://www.planalto.gov.br/ccivil/decreto-lei/del3689.htm>. Acesso em: 04 out. 2010.

45 ASSOCIAÇÃO BRASILEIRA DE MEDICINA LEGAL. Disponível em: <http://www.abml-medicinalegal. org.br/institucional/quemsomos.php>. Acesso em: 4 out. 2010. 